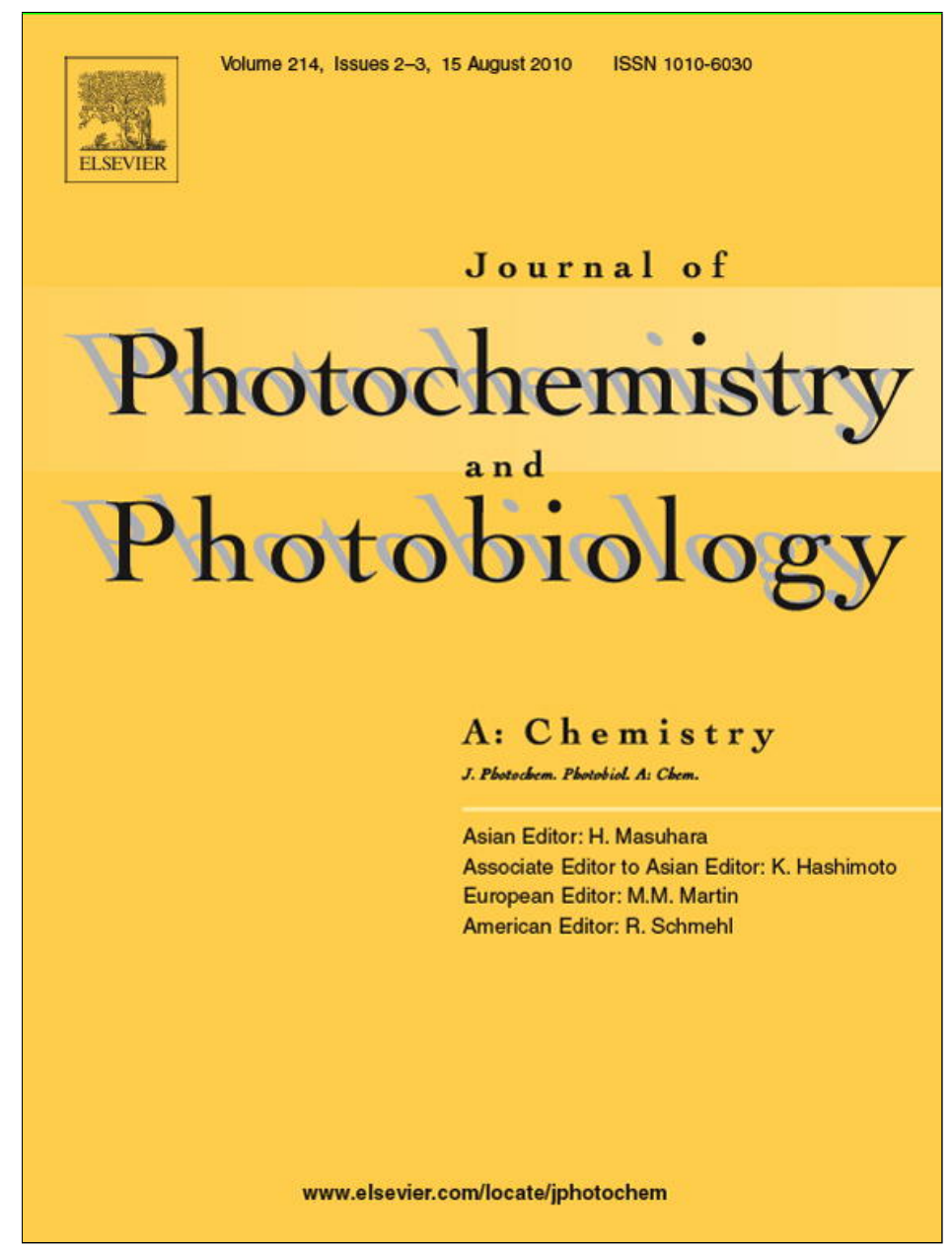

This article appeared in a journal published by Elsevier. The attached copy is furnished to the author for internal non-commercial research and education use, including for instruction at the authors institution and sharing with colleagues.

Other uses, including reproduction and distribution, or selling or licensing copies, or posting to personal, institutional or third party websites are prohibited.

In most cases authors are permitted to post their version of the article (e.g. in Word or Tex form) to their personal website or institutional repository. Authors requiring further information regarding Elsevier's archiving and manuscript policies are encouraged to visit:

http://www.elsevier.com/copyright 


\title{
Effect of the radiation flux on the photocatalytic inactivation of spores of Bacillus subtilis
}

\author{
Silvia Mercedes Zacarías ${ }^{\mathrm{a}, \mathrm{b}}$, María Celia Vaccari ${ }^{\mathrm{a}}$, Orlando Mario Alfano ${ }^{\mathrm{b}, *}$, \\ Horacio Antonio Irazoqui ${ }^{\mathrm{a}, \mathrm{b}}$, Gustavo Eduardo Imoberdorfa, \\ ${ }^{a}$ Facultad de Bioquímica y Ciencias Biológicas, Universidad Nacional del Litoral, Ruta Nacional 168 Paraje el Pozo, 3000 Santa Fe, Argentina \\ ${ }^{\mathrm{b}}$ Instituto el Desarrollo Tecnológico para la Industria Química, Universidad Nacional del Litoral and Consejo Nacional de Investigaciones Científicas y Técnicas, \\ Güemes 3450, 3000 Santa Fe, Argentina
}

\section{A R T I C L E I N F O}

\section{Article history:}

Received 23 March 2010

Received in revised form 7 June 2010

Accepted 15 June 2010

Available online 23 June 2010

\section{Keywords:}

Inactivation

Spores

Bacillus subtilis

Photocatalysis

UV-A

\begin{abstract}
A B S T R A C T
In this paper, the photocatalytic inactivation of dry spores of Bacillus subtilis dispersed on $\mathrm{TiO}_{2}$ films and irradiated with UV-A radiation $\left(2.44-0.29 \mathrm{~mW} \mathrm{~cm}^{-2}\right)$ was studied. Experimental results indicate a minor reduction in the number of viable spores (69\% of inactivation after $48 \mathrm{~h}$ of irradiation) when they were irradiated with UV-A radiation on borosilicate glass plates (without $\mathrm{TiO}_{2}$ ), confirming the resistance of spores to UV-A radiation. However, the number of viable spores significantly decreased when they were irradiated with UV-A under similar conditions but on plates coated with $\mathrm{TiO}_{2}(99.88 \%$ of inactivation after $24 \mathrm{~h}$ of irradiation), showing that dry spores of $B$. subtilis are vulnerable to photocatalytic inactivation. A simplified scheme was proposed to model the photocatalytic inactivation of $B$. subtilis, from which a kinetic expression was derived. Since the rate of photocatalytic inactivation is strongly dependent on the flux of the UV radiation on the $\mathrm{TiO}_{2}$ films, the radiation field was modeled by means of CFD software. Experimental results of spore inactivation were fitted with the derived kinetic expression, showing the inactivation rate has a square root dependence on the radiation flux reaching the photocatalyst film.
\end{abstract}

(C) 2010 Elsevier B.V. All rights reserved.

\section{Introduction}

Environmental regulations are establishing increasingly stringent controls over air contamination. In particular, indoor air contamination is an important area of concern because people spend an average of $80-90 \%$ of their time indoors [1]. Indoor air contaminants include several chemical compounds, airborne solid particles, and biological contaminants in the form of bioaerosols. The latter represents one of the major contributors to indoor air pollution. In general terms, bioaerosols may carry vegetative cells and spores of bacteria and fungi, viruses, and metabolic products from microorganisms [2]. The presence of bioaerosols in indoor air can cause allergic responses, infectious diseases, and respiratory problems.

Although most of the microorganisms dispersed in air are vegetative cells, a significant proportion are in the form of spores, which have distinctive characteristics crucial to their survival under unfavourable atmospheric conditions. The low metabolism of

\footnotetext{
* Corresponding author at: Universidad Nacional del Litoral, Chemical Reaction and Reactor Engineering, Güemes 3450, 3000Santa Fe, Santa Fe, Argentina.

Tel.: +54 342 4511546; fax: +543424511170

E-mail addresses: alfano@santafe-conicet.gov.ar, alfano@intec.unl.edu.ar (O.M. Alfano).
}

spores allows them to remain viable for large periods of time without requiring external nutrients or even water. In addition, spores are quite resilient to moderate temperatures and low humidity levels, even in the presence of chemical agents and ionizing radiation.

Photocatalysis is considered an interesting technological alternative for the decontamination of polluted air and water from different sources. Photocatalytic processes are based on the generation of highly oxidizing species, such as $\bullet \mathrm{OH}$ radicals, which takes place when a semiconductor (generally $\mathrm{TiO}_{2}$ ) absorbs UV radiation. The effectiveness of photocatalytic processes has been proven for the abatement of many organic pollutants, including alcohols, ketones, aromatic and nitrogen compounds, and halogenated organic compounds present in water and air [3-9].

The applicability of photocatalysis for the inactivation of contaminating microorganisms in water and air has been studied in recent years. The pioneering work in this area was conducted by Matsunaga et al. [10] and focused on the elimination of Lactobacillus acidophilus, Saccharomyce cerevisiae, Escherichia coli, and Chlorella vulgaris from contaminated water using suspended $\mathrm{TiO}_{2}-\mathrm{Pt}$ particles irradiated with UV-A. The authors argued that the cause of the photocatalytic inactivation of these bacteria is related to the degradation of the co-enzyme $\mathrm{A}$, producing the inhibition of cell respiration. Several subsequent studies related to the bactericidal effect of $\mathrm{TiO}_{2}$ photocatalyst have been carried out to inactivate bacteria, viruses, and fungi present in contaminated water [11-23]. 


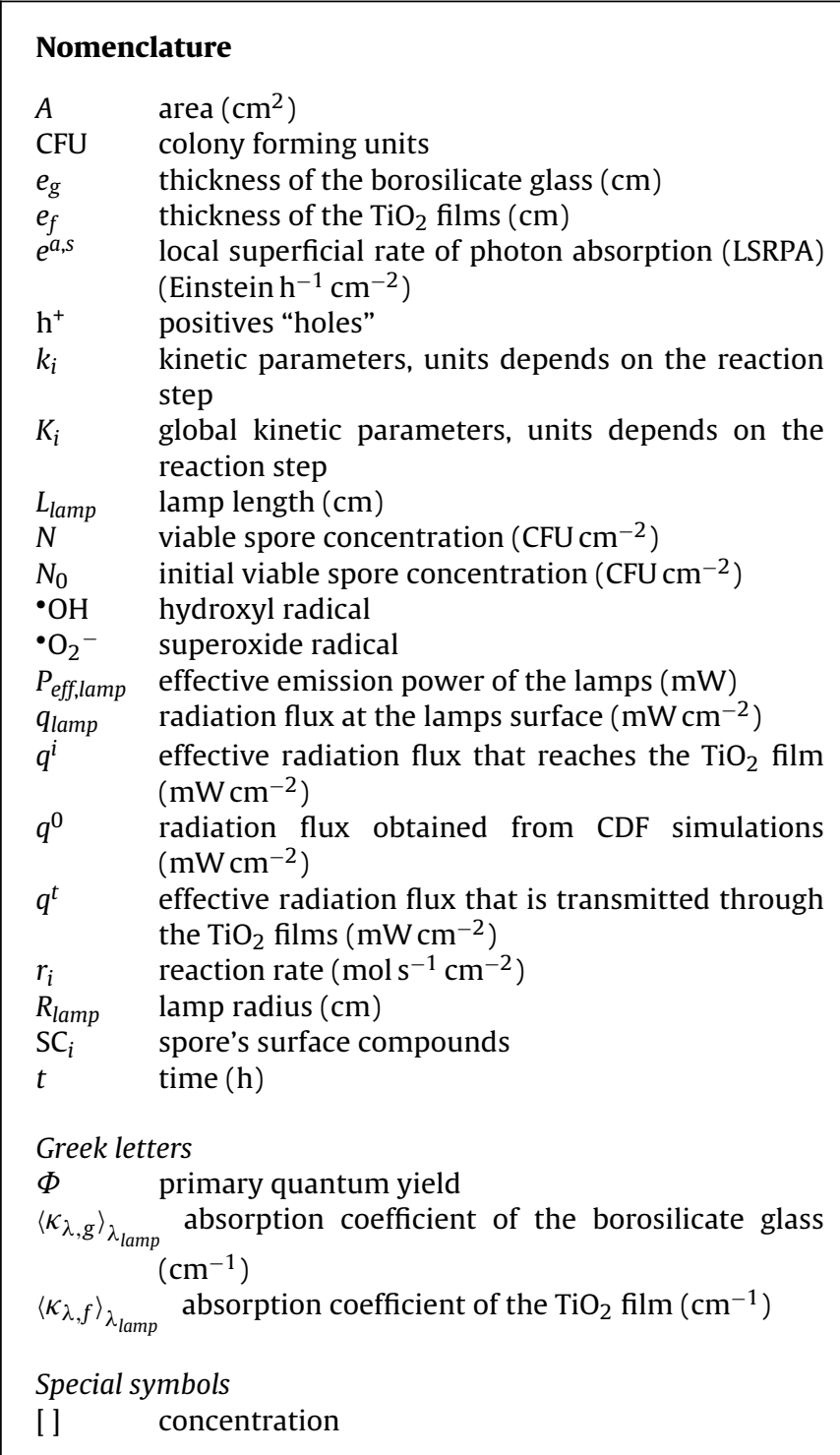

However, only a small number of studies addressing the subject of photocatalytic inactivation of bioaerosols present in indoor air can be found in the literature. Goswami et al. [24] reported the total inactivation of Serratia marcescens in a photocatalytic reactor with recirculation. The photocatalytic inactivation of bioaerosols was also the subject of a handful of more recent publications [25-38].

The use of photocatalytic process to degrade spores immobilized on a $\mathrm{TiO}_{2}$-coated surface was first reported by Wolfrum et al. [27]. The authors reported that complete mineralization of bacteria, bac- terial and fungal spores, and biofilm components can be obtained on Degussa P25 $\mathrm{TiO}_{2}$-coated surfaces irradiated with UV-A radiation. The mineralization degree was estimated from measurements of the $\mathrm{CO}_{2}$ released after the photocatalytic reactions. In particular, the authors determined that when Bacillus subtilis spores are irradiated with $10.4 \mathrm{~mW} \mathrm{~cm}^{-2} \mathrm{UV}-\mathrm{A}$ on a $\mathrm{TiO}_{2}$-coated surface during $24 \mathrm{~h}$, the mineralization extent is nearly $90 \%$. Lin and Li [30] studied the photocatalytic inactivation of $B$. subtilis and Penicillium citrinum spores. The authors employed a commercially available $\mathrm{TiO}_{2}$ filter and a slide coated with $\mathrm{TiO}_{2}$, which were irradiated with UV-A radiation. They concluded that the exposure of spores spread on $\mathrm{TiO}_{2}$ surfaces to increase radiation fluxes of UV radiation produces higher inactivation rates.

Design and optimization of chemical reactors, regardless of their final application, require knowing the effect of the radiation flux and the kinetics of the chemical process involved. However, there are only few papers in which kinetic models describing photocatalytic inactivation of immobilized microorganisms are linked to the relevant operating variables, such as microorganism concentration, radiation flux on the catalytic surface, and exposition time or residence time. In this regard, Sato et al. [29] developed a model of the photocatalytic inactivation kinetics of $E$. coli immobilized on quartz plates covered with $\mathrm{TiO}_{2}$. Moreover, Pal et al. [31] studied the inactivation kinetics of E. coli, B. subtilis and Microbacterium sp.

In this work, the effect of the radiation flux on the photocatalytic inactivation of $B$. subtilis spores on UV-irradiated $\mathrm{TiO}_{2}$ films supported on borosilicate glass plates was study. Also a kinetic expression of the photocatalytic inactivation rate was derived from an inactivation scheme which, although simple, still retains the essentials of the intervening events and the influence of each relevant operating variable upon the whole process. The rate of photon absorption in the $\mathrm{TiO}_{2}$ catalyst, which represents one of the most important variables affecting the photocatalytic reaction rate, was predicted by using CFD software (Fluent 6.3). The kinetic expression derived from the proposed inactivation scheme considers the effect of the rate of photon absorption, the concentration of viable spores, and the irradiation time on the spore inactivation rate.

\section{Materials and methods}

\subsection{Experimental setup}

The photocatalytic reactor employed in this work is sketched in Fig. 1. It is comprised of a UV-radiation emitting system, an irradiation compartment, and a support to hold borosilicate glass plates (bare or coated with $\mathrm{TiO}_{2}$ ) with the spore samples while they are irradiated. The UV-radiation emitting system (Fig. 1.a) consists of a set of seven tubular black-light fluorescent lamps (YLX 8W/BLB) held by a metallic rectangular box above the irradiation compartment in a horizontal parallel arrangement. The emission spectrum of the lamps, shown in Fig. 2, is between 300 and $420 \mathrm{~nm}$, with a maximum at about $350 \mathrm{~nm}$ (UV-A).
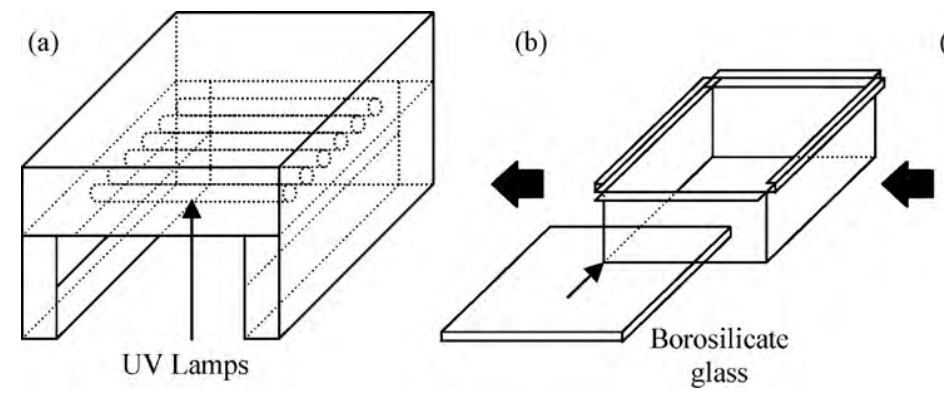

(c)

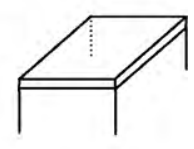

Fig. 1. Diagram of the experimental setup: (a) UV-radiation emitting system, (b) irradiation compartment, (c) glass support. 


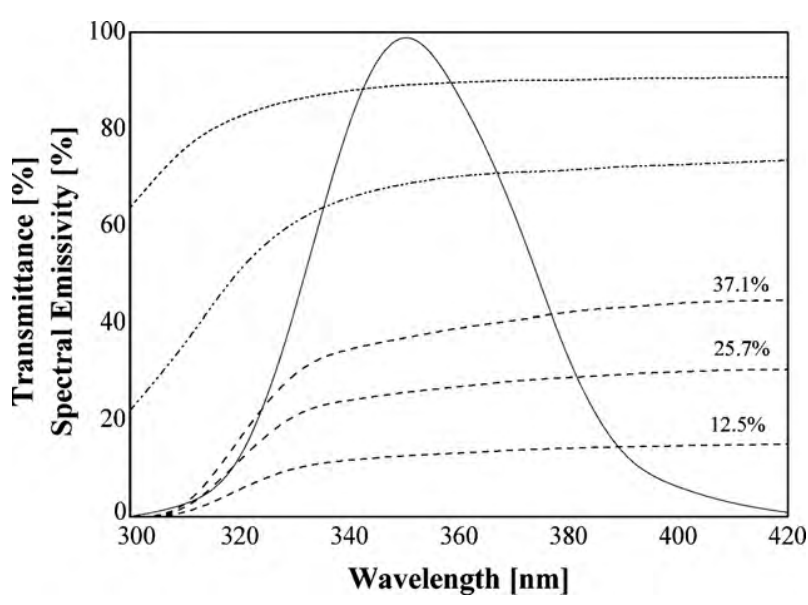

Fig. 2. Spectral emission of the lamps (-) and spectral transmittances of the neutral filters (----), of the bare borosilicate glass ( $\cdots \cdots)$, and of the $\mathrm{TiO}_{2}$-coated borosilicate glass (-..-).

The irradiation compartment consists of a metallic rectangular box with a sliding removable borosilicate glass plate (Fig. 1b). To simplify the radiation model, the internal walls of this compartment were covered with opaque black paint to minimize the reflection of radiation. The UV radiation generated by the emission system entered this compartment through the glass cover, which also prevented spore samples from being contaminated during the irradiation. The photocatalytic plates with spore samples were horizontally held at the central zone of the irradiation compartment, where the radiation flux was almost uniform, and placed on a 4.5 -cm-high, 9-cm-wide, and 15-cm-long glass support (Fig. 1c). In order to secure an atmosphere with the high relative humidity necessary to obtain a sustainable photocatalytic activity of $\mathrm{TiO}_{2}$, a distilled water-filled Petri dish was included in the irradiation compartment. During all the experimental runs, the relative humidity and temperature inside the irradiation compartment was measured with a thermohygrometer (Mannix PTH8708 Thermo-Hygrometer TH Pen). Although the designed photocatalytic reactor does not have an automated control of humidity and temperature, both operating conditions remained approximately constant during experimental runs (Table 1). Experiments were carried out at four different irradiation levels (at 2.44, 0.90, 0.63 and $0.29 \mathrm{~mW} \mathrm{~cm}^{-2}$ ). The irradiation level reaching the spore samples was varied by interposing neutral optical filters between the UVradiation emitting system and the irradiation compartment. The optical characteristics of these neutral optical filters and the lamp's spectral emission distribution are shown in Fig. 2.

\subsection{Preparation of the photocatalytic plates}

Photochemical inactivation was studied by irradiating spores on bare borosilicate glass plates, whereas the photocatalytic inactivation was examined by irradiating spores on $\mathrm{TiO}_{2}$-coated borosilicate glass plates. The size of the plates was $2 \mathrm{~cm} \times 2 \mathrm{~cm}$ in all cases. The $\mathrm{TiO}_{2}$ thin films were obtained through a sol-gel tech- nique that uses titanium tetra-isopropoxide as precursor [39]. First, the hydrolysis of the titanium tetra-isopropoxide was conducted in an acid aqueous medium. A volume of $415 \mathrm{~cm}^{3}$ of triple-distilled water was mixed with $4.5 \mathrm{~cm}^{3}$ of concentrated nitric acid (Anedra, $65 \%$ ), and $35 \mathrm{~cm}^{3}$ of titanium isopropoxide (Aldrich, 97\%) was added to this mixture. Under such conditions, the hydrolysis of the precursor proceeded vigorously, producing large lumps of hydrated $\mathrm{TiO}_{2}$. The dispersion of the lumped particles was achieved by stirring the suspension over a period of $10 \mathrm{~h}$ at $80^{\circ} \mathrm{C}$, until a clear sol of $\mathrm{TiO}_{2}$ nano-particles was obtained. Before the $\mathrm{TiO}_{2}$ immobilization, the borosilicate glass plates were washed with isopropyl alcohol and triple-distilled water for $20 \mathrm{~min}$ under sonication. Then, they were heated during $8 \mathrm{~h}$ at $500^{\circ} \mathrm{C}$ to remove any trace of organic materials that might still remain on the surface. The $\mathrm{TiO}_{2}$ films were deposited by dip-coating the glass plates in the liquid mixture at a withdrawal speed of $3 \mathrm{~cm} \mathrm{~min}^{-1}$ at room temperature $\left(25^{\circ} \mathrm{C}\right)$. The plates were dried in an oven at $80^{\circ} \mathrm{C}$ and then heated at $200^{\circ} \mathrm{C}$ for $6 \mathrm{~h}$ to increase the adherence of the thin film and to induce the formation of the anatase phase, which is the most active crystalline form of $\mathrm{TiO}_{2}$ for photocatalytic applications. The amount of $\mathrm{TiO}_{2}$ deposited on the borosilicate glass plates was measured by a titration procedure that involves the spectrophotometric determination of the peroxotitanate formed from titanium sulfate and hydrogen peroxide. The average superficial weight of $\mathrm{TiO}_{2}$ on the covered glass was $0.023 \mathrm{mg} \mathrm{cm}^{-2}$.

\subsection{Spores formation and collection}

In this work, B. subtilis spores (ATCC 6633 strain) were adopted as the model microorganism. Suspensions of spores in distilled water were obtained following the technique proposed by Shehata and Collins [40]. A Roux bottle containing a sporulation medium, which consisted of nutritive agar (Britania Laboratories) with $0.05 \%$ $\mathrm{MnSO}_{4}$ and $0.05 \% \mathrm{MgSO}_{4}$, was inoculated and incubated at $30^{\circ} \mathrm{C}$ during a 7-10-day period. Then, the spores and vegetative cells obtained were recovered by washing the surface of the sporulation medium with sterile buffer phosphate $(\mathrm{pH}=6.8)$. After that, the spores recovered were centrifuged three times in $15 \mathrm{~min}$ at $3500 \mathrm{rpm}$ with the same buffer. The suspension was kept at $30^{\circ} \mathrm{C}$ during $48-72 \mathrm{~h}$ to induce vegetative cell lysis. Then, the vegetative cells and the spores were washed again according to the instructions outlined above. This method was repeated three times to wash the cells. The spore suspension was suspended in sterile distilled water and conserved at $4{ }^{\circ} \mathrm{C}$.

\subsection{Irradiation of the spore samples}

Before starting the irradiation experiment, aliquots of $1 \mathrm{~mL}$ of the suspension spores were kept at $80^{\circ} \mathrm{C}$ during $10 \mathrm{~min}$ to eliminate the remaining vegetative cells. After that, aliquots of $10 \mu \mathrm{L}$ volume each of the spore suspension were spread to cover a $1.5-\mathrm{cm}^{2}$ surface on both glass plates covered with photocatalytic $\mathrm{TiO}_{2}$ films and bare glass plates. Afterwards, the plates were kept at $30^{\circ} \mathrm{C}$ during a $1-\mathrm{h}$ period while the spore samples dried. Then, the dried plates were introduced into the irradiation compartment, in which they were

Table 1

Summary of temperature and humidity inside the radiation compartment.

\begin{tabular}{|c|c|c|c|c|}
\hline \multirow[t]{2}{*}{ Irradiation time $[\mathrm{h}]$} & \multicolumn{2}{|c|}{ Spores irradiated without $\mathrm{TiO}_{2}\left(2.44 \mathrm{~mW} \mathrm{~cm}^{-2}\right)$} & \multicolumn{2}{|c|}{ Spores irradiated with $\mathrm{TiO}_{2}\left(2.44 \mathrm{~mW} \mathrm{~cm}^{-2}\right)$} \\
\hline & Temperature $\left[{ }^{\circ} \mathrm{C}\right]$ & Humidity [\%] & Temperature $\left[{ }^{\circ} \mathrm{C}\right]$ & Humidity [\%] \\
\hline 6 & 29.7 & 78.7 & 32.5 & 75.3 \\
\hline 12 & 30.8 & 72.3 & 34.2 & 78.9 \\
\hline 24 & 29.8 & 70.1 & 31.3 & 82.7 \\
\hline 36 & 33.7 & 77.5 & 32.4 & 78.8 \\
\hline 48 & 31.5 & 78.6 & 33.6 & 81.0 \\
\hline
\end{tabular}




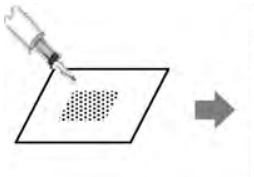

Spores

immobilization

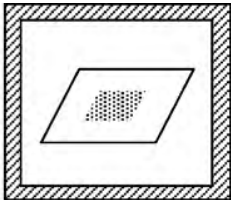

Drying of the

samples

$\left(80^{\circ} \mathrm{C} / 1 \mathrm{~h}\right)$

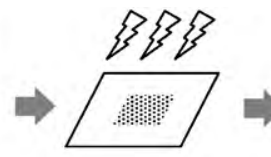

Irradiation

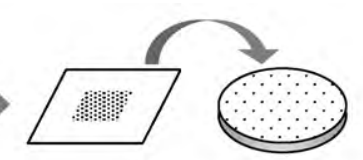

Washing of the
resulting
samples
CFU

determination

Fig. 3. Schematic representation of the experimental procedure.

exposed to a given irradiation level at different times $(6,12,24$ or $48 \mathrm{~h}$ ). Once the irradiation time programmed for each sample had elapsed, the corresponding glass plates were removed from the irradiation compartment, and the remaining viable spores were counted.

\subsection{Measurement of spore viability}

The counting of viable spores on $\mathrm{TiO}_{2}$-coated and bare plates was done according to the following technique. First, a given plate with the spore sample was placed in a Falcon tube with $10 \mathrm{~mL}$ of sterile extraction solution ( $0.1 \%$ peptone in sterile distilled water). Then, the spore sample was gently scraped using a small sterile spatula to detach the spores from the plate surface. The Falcon tube containing the glass plate, the spatula, and the extracting solution was shaken at $200 \mathrm{rpm}$ for $15 \mathrm{~min}$. Aliquots of $1 \mathrm{~mL}$ of the resulting suspension were spread onto agar plates, incubated for $48 \mathrm{~h}$ at $30^{\circ} \mathrm{C}$, and the colony forming units (CFU) were counted. When necessary, the extraction solutions were conveniently diluted with a $0.1 \%$ peptone solution before the quantification step to obtain 30-300 CFU. The tests were repeated twice for each experimental condition studied, and each repetition was made in duplicate. In preliminary experiments, the washing efficiency for spore recovery was evaluated, and the value obtained was greater than $90 \%$.

\section{Results and discussion}

\subsection{Experimental results}

As mentioned, photocatalytic inactivation of $B$. subtilis spores was measured by exposing dry spores in contact with $\mathrm{TiO}_{2}$ to UV radiation, whereas the photochemical inactivation was measured by exposing dry spores to $\mathrm{UV}$ radiation (without $\mathrm{TiO}_{2}$ ). Experiments were carried out by exposing spore samples at four irradiation levels $\left(2.44,0.90,0.63\right.$ and $\left.0.29 \mathrm{~mW} \mathrm{~cm}^{-2}\right)$ during different times $(0,6$, $12,24,36$, and $48 \mathrm{~h}$ ). In order to measure the inactivation extent, the survival spores, those that remained viable after irradiation, were measured (Fig. 3). They are expressed as [N], which represents the colony forming units per square centimeter $\left(\mathrm{CFU} \mathrm{cm} \mathrm{cm}^{-2}\right)$.

Fig. 4 shows the experimental results obtained when spore samples on $\mathrm{TiO}_{2}$-coated plates and bare plates were exposed to UV-A radiation $\left(2.44 \mathrm{~mW} \mathrm{~cm}^{-2}\right)$ during different periods of time. As also shown in Fig. 4, trendlines were plotted to facilitate observation of the reduction of spore viability.

When $B$. subtilis spores were irradiated over $\mathrm{TiO}_{2}$ surfaces, their viability decreased significantly and the inactivation extent increased with the irradiation time. After $24 \mathrm{~h}$ of continuous irradiation of spore samples spread on $\mathrm{TiO}_{2}$-coated plates, the fraction of viable spores was close to $0.12 \%$. When the samples were irradiated for a longer period of time, the number of viable spores was lower than the detection limit of the quantification procedure $\left(6.7 \times 10^{2} \mathrm{CFU} \mathrm{cm} \mathrm{cm}^{-2}\right)$. However, when spore irradiation was conducted under the same experimental conditions but with the spores of $B$. subtilis spread on glass plates without $\mathrm{TiO}_{2}$, there

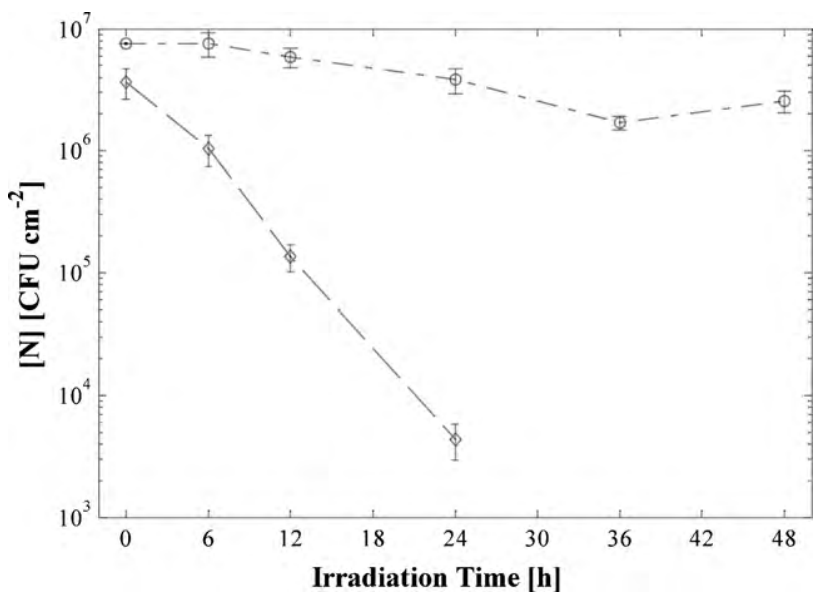

Fig. 4. Inactivation curves for different irradiation times of spores irradiated on bare plates $(\bigcirc)$ and spores irradiated on $\mathrm{TiO}_{2}$-coated plates $(\diamond)$ for an incident radiation flux of $2.44 \mathrm{~mW} \mathrm{~cm}^{-2},(---)$ tendency line of spores on $\mathrm{TiO}_{2}$-coated plates, $(----)$ tendency line of spores on bare plates.

was little spore inactivation (Fig. 4). After $48 \mathrm{~h}$ of continuous irradiation, the fraction of viable spores was close to $31 \%$, showing that under the operating conditions employed, the purely photochemical inactivation was not significant when compared to the photocatalytic inactivation. The order of magnitude of the reduction of spores irradiated on borosilicate glass (without $\mathrm{TiO}_{2}$ ) under the aforementioned conditions was about 0.47 after $48 \mathrm{~h}$ of continuous irradiation, whereas those irradiated on $\mathrm{TiO}_{2}$ films was greater than 3 after $24 \mathrm{~h}$ of continuous irradiation. The different resistance levels observed between spores irradiated on $\mathrm{TiO}_{2}$ films from those on bare glass plates confirms that, under the employed conditions, B. subtilis spores are much more vulnerable to photocatalytic inactivation than to photochemical inactivation.

For all the irradiation levels employed, the viability of spores spread on glass plates covered with $\mathrm{TiO}_{2}$ films significantly diminished with the exposition time. Table 2 shows a summary of experimental results obtained when spores samples on $\mathrm{TiO}_{2}-$ coated plates were exposed to different incident radiation fluxes. Regarding the effect of the irradiation level on the photocatalytic inactivation rate, experimental results show that the more intense

Table 2

Summary of results obtained with spores spread on $\mathrm{TiO}_{2}$ films.

\begin{tabular}{cllll}
\hline Irradiation time $[\mathrm{h}]$ & \multicolumn{4}{l}{$N\left[\mathrm{CFU} \mathrm{cm}{ }^{-2}\right]$} \\
\cline { 2 - 5 } & \multicolumn{4}{l}{ Incident radiation flux $\left[\mathrm{mW} \mathrm{cm}^{-2}\right]$} \\
\cline { 2 - 5 } & 2.44 & 0.90 & 0.63 & 0.29 \\
\hline 0 & $3.67 \times 10^{6}$ & $1.19 \times 10^{7}$ & $1.73 \times 10^{6}$ & $2.43 \times 10^{6}$ \\
6 & $1.04 \times 10^{6}$ & $2.00 \times 10^{6}$ & $8.83 \times 10^{5}$ & $8.67 \times 10^{5}$ \\
12 & $1.36 \times 10^{5}$ & $9.22 \times 10^{5}$ & $3.23 \times 10^{5}$ & $5.65 \times 10^{5}$ \\
24 & $4.33 \times 10^{3}$ & $2.56 \times 10^{5}$ & $7.65 \times 10^{4}$ & $1.73 \times 10^{5}$ \\
36 & - & $3.20 \times 10^{4}$ & - & $8.80 \times 10^{4}$ \\
48 & - & $7.33 \times 10^{3}$ & $2.00 \times 10^{3}$ & $2.43 \times 10^{4}$ \\
\hline
\end{tabular}


the radiation flux reaching the photocatalytic plate is, the faster the spore inactivation progresses. The relationship between the inactivation rate and the radiation flux will be analyzed in the following sub-section using the kinetic model.

\subsection{Microbiological interpretation of the photochemical resistance and the photocatalytic vulnerability of spores}

Bacterial endospores are generally highly resistant to UV radiation, even to high-energy short wavelengths, such as UV-B and UV-C radiation [41]. The extremely high resistance of spores to purely UV-A photochemical inactivation has been explained by considering several of their distinctive characteristics closely related to their structure, morphology and chemical composition [42]. Lin and $\mathrm{Li}$ [30] informed photochemical inactivation of spores of $B$. subtilis exposed to $0.75 \mathrm{~mW} \mathrm{~cm}^{-2}$ of UV-A. Otherwise, Vohra et al. [32] reported that $B$. cereus spores samples exposed to a very high radiation flux $\left(50 \mathrm{~mW} \mathrm{~cm}^{-2}\right)$ of UV-A during 24 h are only inactivated by a $50 \%$. Moreover, Zhao et al. [38] reported photochemical inactivation at higher UV-A irradiance $\left(8.4-15.3 \mathrm{~mW} \mathrm{~cm}^{-2}\right)$. They found a linear relationship between UV-A irradiance and the rate of spore inactivation in the absence of photocatalyst.

On the other hand, the vulnerability of spores to photocatalytic attack can be explained by considering the features of the photocatalytic process together with the spore structure. In broad terms, photocatalytic processes are based on the action of highly oxidative, short lived, intermediate compounds that are generated when a semiconductor (e.g., $\mathrm{TiO}_{2}$ ) is activated by UV radiation. In particular, - $\mathrm{OH}$ radicals are highly reactive since they are able to capture electrons easily from organic compounds causing their oxidation. From this perspective, the photocatalytic viability loss of spores could be explained by a complex mechanism that begins when their external protective coat is degraded, mainly by the combined oxidative attack of the ${ }^{\bullet} \mathrm{OH}$ radicals and the positive "holes" $\left(\mathrm{h}^{+}\right)$near the catalyst surface. Although the degradation of the pore's outer coat is not necessarily lethal since the spore may still keep its ability to germinate, once the protective wall is removed to the extent of letting the free radicals reach the protoplast and its membrane, then lethal events will very likely take place [7]. Lin and $\mathrm{Li}[30]$ reported that the time for $90 \%$ inactivation for $\mathrm{B}$. subtilis on the $\mathrm{TiO}_{2}$ slide irradiated with $0.74 \mathrm{~mW} \mathrm{~cm}^{-2}$ was $2.15 \mathrm{~h}$. Also, Vohra et al. [32] reported that $99 \%$ of $B$. cereus spores exposed to a $50 \mathrm{~mW} \mathrm{~cm}^{-2}$ of UV-A over $\mathrm{TiO}_{2}$ during $24 \mathrm{~h}$ was inactivated, and $100 \%$ of $B$. cereus spores exposed to a $50 \mathrm{~mW} \mathrm{~cm}^{-2}$ of UV-A over $\mathrm{Ag}-\mathrm{TiO}_{2}$ during $4 \mathrm{~h}$ was inactivated. Also, Zhao et al. [38] reported that inactivation of spores at low UVA irradiance $\left(3 \mathrm{~mW} \mathrm{~cm}^{-2}\right)$ was primarily due to photocatalysis, and the inactivation rate coefficient with $\mathrm{TiO}_{2}$ under UV-A irradiation was three times the rate with UV-A alone. They found that the rate of photocatalytic inactivation was non-linear with respect to UV-A irradiance, exhibiting a maximum at $3 \mathrm{~mW} \mathrm{~cm}^{-2}$.

\subsection{Simplified photocatalytic inactivation reaction pathway}

There are a wide range of hypotheses in the literature regarding which species are responsible for the degradation of microorganisms in photocatalytic processes developed for the disinfection of water [12-15] and air [31,32]. Although all authors agree that the main oxidant is $\bullet \mathrm{OH}$ radical, very few identify what is responsible for the microorganisms' inactivation. Both Sun et al. [43] and Cho et al. [44] worked with E. coli in water disinfection, and they explicitly raise the species $\mathrm{h}^{+}$and $\bullet \mathrm{OH}$ radical as those responsible for the inactivation of this microorganism.

A simplified scheme for the complex photocatalytic inactivation process of spores of $B$. subtilis is proposed. The sequence of reaction steps and their corresponding kinetic expressions are shown in Table 3 . The first step corresponds to the semiconductor activa-
Table 3

Reaction pathway.

\begin{tabular}{lll}
\hline $\mathrm{N}^{0}$ & Reaction step & Step reaction rate \\
\hline$(1)$ & $\mathrm{TiO}_{2}+h v \rightarrow \mathrm{TiO}_{2}+\mathrm{h}^{+}+\mathrm{e}^{-}$ & $r_{1}=\Phi e^{a, s}$ \\
$(2)$ & $\mathrm{h}^{+}+\mathrm{H}_{2} \mathrm{O}_{(\mathrm{ads})} \rightarrow \cdot \mathrm{OH}+\mathrm{H}^{+}$ & $r_{2}=k_{2}\left[\mathrm{~h}^{+}\right]\left[\mathrm{H}_{2} \mathrm{O}\right]_{\text {ads }}$ \\
$(3)$ & $\mathrm{e}^{-}+\mathrm{O}_{2} \rightarrow \mathrm{O}_{2}^{-}$ & $r_{3}=k_{3}\left[\mathrm{e}^{-}\right]\left[\mathrm{O}_{2}\right]$ \\
$(4)$ & $2 \cdot \mathrm{OH} \rightarrow \mathrm{H}_{2} \mathrm{O}_{2}$ & $r_{4}=2 k_{4}\left[\bullet^{\bullet} \mathrm{OH}\right]^{2}$ \\
$(5)$ & $\mathrm{h}^{+}+$surface compounds $\rightarrow$ products & $r_{5}=k_{5}\left[\mathrm{~h}^{+}\right][\mathrm{SC}]$ \\
$(6)$ & $\bullet \mathrm{OH}+$ surface compounds $\rightarrow$ Products & $r_{6}=k_{6}\left[\bullet^{\bullet} \mathrm{OH}\right][\mathrm{SC}]$ \\
$(7)$ & $\bullet \mathrm{OH}+$ viable spores $\rightarrow$ inactive spores & $r_{7}=k_{7}\left[\bullet^{\circ} \mathrm{OH}\right][\mathrm{N}]$ \\
$(8)$ & $\mathrm{h}^{+}+\mathrm{e}^{-} \rightarrow$ thermal energy & $r_{8}=k_{8}\left[\mathrm{~h}^{+}\right]\left[\mathrm{e}^{-}\right]$ \\
\hline
\end{tabular}

tion process by the absorption of photons of UV radiation (reaction (1)) with energy quanta large enough to release electrons originally bonded to nuclei of the lattice (i.e., electrons in the lattice valence energy band), thus becoming free conduction electrons (i.e., electrons in the lattice conduction energy band). The rate of this initial step is proportional to the local rate at which photons are absorbed on the photocatalytic film. The proportionality constant $\Phi$ is the primary quantum yield, meaning that the fraction of absorbed photons of energy is larger than (or equal to) the band gap between the semiconductor valence band and the conduction band, which actually promotes electrons from the first to the second band. During their lifetime, the photo-generated $\mathrm{h}^{+}$may interact with water molecules adsorbed on the catalyst surface to produce ${ }^{\bullet} \mathrm{OH}$ radicals (reaction (2)), while free electrons $\left(\mathrm{e}^{-}\right.$) may be transferred to adsorbed molecular oxygen thus generating - $\mathrm{O}_{2}$ - radicals (reaction (3)), which are strong oxidizing and reducing species, respectively. In addition, ${ }^{\circ} \mathrm{OH}$ radicals may react with each other to form $\mathrm{H}_{2} \mathrm{O}_{2}$ (reaction (4)). Nevertheless, such an event requires that two ${ }^{\circ} \mathrm{OH}$ radicals collide with each other during their short lifetime, which is a very unlikely event. As a consequence of this, we may assumed that reaction (4) will progress at a very slow rate and the concentration of $\mathrm{H}_{2} \mathrm{O}_{2}$ will be negligible. For modeling purposes, it is proposed that the spore is composed of a single coat, including the inner and outer coat, and the cortex of the spore. The photo-generated $\mathrm{h}^{+}$may interact directly with the compounds of the spore coat (reaction (5)). Although not considered to be the reactive species responsible for inactivation of spores, this reaction is likely to occur and can work with primary oxidation carried out by ${ }^{\circ} \mathrm{OH}$ radicals. Step (6) represents the progressive photocatalytic degradation of the compounds of the spore coat at its point of contact with the photocatalytic surface, which does not cause lethal injuries to the spores. Step (7) represents the loss of spore viability, to obtain inactive spores, which could be due both to loss of coat integrity, as core damage, or both processes together. For the modeling purposed, inactive spores are assumed to differ from the active ones only in their ability to germinate. The last step is the recombination of $\mathrm{h}^{+}$and $\mathrm{e}^{-}$(reaction (8)) with simultaneous energy release.

At the beginning of the process, all the spores on the photocatalytic surface are intact, but after the irradiation process starts, the organic compounds of the spore's coat are progressively oxidized. Also, the core starts being oxidized. The damage in the coat and in the core is accumulative, and the initially intact spores evolve through states of increasing degradation extent. When this damage reaches a level that cannot be repaired or reversed by the spores during germination, then the spore is inactive. Eventually, according to the results of Wolfrum et al. [27], the spores could be completely mineralized. Considering the irradiation levels and the exposure times adopted in this work, mineralization is not expected to occur under our experimental conditions.

In addition to the oxidizing effect of ${ }^{\bullet} \mathrm{OH}$ and $\mathrm{h}^{+}$, there are other species which could contribute to the spore inactivation, such as superoxide radicals $\left(\bullet^{\bullet} \mathrm{O}_{2} \mathrm{H} / \bullet^{\bullet} \mathrm{O}_{2}{ }^{-}\right)$and $\mathrm{H}_{2} \mathrm{O}_{2}$, whose effects could be incorporated into the model by including the corresponding reac- 
tions in the pathway, analogous to reactions (5)-(7) in Table 3. However, since the concentration of superoxide radicals and $\mathrm{H}_{2} \mathrm{O}_{2}$ is expected to be very low, it was assumed that their contribution to the spore inactivation is negligible. There are several contributions which indicate that the $\bullet^{\circ} \mathrm{OH}$ radical is the primary oxidant species responsible for inactivating microorganisms in the photocatalytic process $[12-14,31,32,45]$. It has been also demonstrated by a quantitative study the primary role of the ${ }^{\circ} \mathrm{OH}$ radical in the photocatalytic disinfection process [46].

\subsection{Derivation of the overall kinetic expression for the photocatalytic spore inactivation}

By applying the approximation of zero local net rate of formation (micro steady state approximation) to holes $\left(\mathrm{h}^{+}\right)$and electrons $\left(\mathrm{e}^{-}\right)$ (Table 3), we get:

$$
\begin{aligned}
r_{\mathrm{h}^{+}} & =r_{1}-r_{2}-r_{5}-r_{8} \\
& =\Phi e^{a, s}-k_{2}\left[h^{+}\right]\left[\mathrm{H}_{2} \mathrm{O}\right]_{\mathrm{ads}}-k_{5}\left[h^{+}\right][\mathrm{SC}]-k_{8}\left[h^{+}\right]\left[\mathrm{e}^{-}\right] \approx 0 \\
r_{\mathrm{e}^{-}} & =r_{1}-r_{3}-r_{8}=\Phi e^{a, s}-k_{3}\left[\mathrm{O}_{2}\right]_{\mathrm{ads}}\left[\mathrm{e}^{-}\right]-k_{8}\left[h^{+}\right]\left[\mathrm{e}^{-}\right] \approx 0
\end{aligned}
$$

Then, we find:

$$
\left[\mathrm{h}^{+}\right]=\frac{k_{3}\left[\mathrm{O}_{2}\right]_{\mathrm{ads}}}{2 k_{8}}\left(\sqrt{1+\frac{4 k_{8} \Phi e^{a s}}{k_{3}\left[\mathrm{O}_{2}\right]_{\mathrm{ads}}\left(k_{2}\left[\mathrm{H}_{2} \mathrm{O}\right]_{\mathrm{ads}}+k_{5}[\mathrm{SC}]\right)}}-1\right)
$$

$$
\begin{aligned}
{\left[\mathrm{e}^{-}\right]=} & \frac{\left(k_{2}\left[\mathrm{H}_{2} \mathrm{O}\right]_{\mathrm{ads}}+k_{5}[\mathrm{SC}]\right)}{2 k_{8}} \\
& \times\left(\sqrt{1+\frac{4 k_{8} \Phi e^{a s}}{k_{3}\left[\mathrm{O}_{2}\right]_{\mathrm{ads}}\left(k_{2}\left[\mathrm{H}_{2} \mathrm{O}\right]_{\mathrm{ads}}+k_{5}[\mathrm{SC}]\right)}}-1\right)
\end{aligned}
$$

If the approximation of zero local net rate of formation is also assumed for $\bullet \mathrm{OH}$ radicals, we have:

$$
\begin{aligned}
r \cdot \mathrm{OH}= & r_{2}-r_{4}-r_{6}-r_{7} \approx 0 \\
r \cdot \mathrm{OH}= & k_{2}\left[\mathrm{~h}^{+}\right]\left[\mathrm{H}_{2} \mathrm{O}\right]_{\mathrm{ads}}-2 k_{4}[\bullet \mathrm{OH}]^{2}-k_{6}[\bullet \mathrm{OH}][\mathrm{SC}] \\
& -k_{7}[\bullet \mathrm{OH}][\mathrm{N}] \approx 0
\end{aligned}
$$

In Eq. (6) it can be assumed that radical-radical terminations (reaction (4) in Table 3) are neglected as compared with the photocatalytic degradation. Therefore, we obtain:

$$
\begin{aligned}
{[\bullet \mathrm{OH}]=} & \frac{k_{2}\left[\mathrm{H}_{2} \mathrm{O}\right]_{\mathrm{ads}} k_{3}\left[\mathrm{O}_{2}\right]}{2 k_{8}\left(k_{6}[\mathrm{SC}]+k_{7}[\mathrm{~N}]\right)} \\
& \times\left(\sqrt{1+\frac{4 k_{8} \Phi e^{a s}}{k_{3}\left[\mathrm{O}_{2}\right]_{\mathrm{ads}}\left(k_{2}\left[\mathrm{H}_{2} \mathrm{O}\right]_{\mathrm{ads}}+k_{5}[\mathrm{SC}]\right)}}-1\right)
\end{aligned}
$$

The surface compounds (i.e., [SC]) represent all the chemical compounds components of the spores' coat in direct contact with the $\mathrm{TiO}_{2}$ films. These compounds will act as scavengers of ${ }^{\bullet} \mathrm{OH}$, since they will reduce the availability of $\bullet \mathrm{OH}$ to react with the vital targets of the spore, protecting in this way the spore from being inactivated. Complete mineralization of these surface compounds is very unlikely under the operating conditions utilized, and therefore, no substantial variations of its concentration are expected. For this reason, the concentration of surface compounds was considered constant for modeling purposes.

As far as the concentration of adsorbed water and adsorbed oxygen and the surface compounds remain constant during the irradiation process, we can define the kinetic constants $K_{1}^{\prime \prime}, K_{2}^{\prime}$ and $K_{3}$ :

$[\bullet \mathrm{OH}]=\frac{K_{1}^{\prime \prime}}{\left(1+K_{3}[N]\right)}\left(\sqrt{1+K_{2}^{\prime} e^{a, s}}-1\right)$

where

$K_{1}^{\prime \prime}=\frac{k_{2} k_{3}\left[\mathrm{O}_{2}\right]_{\mathrm{ads}}\left[\mathrm{H}_{2} \mathrm{O}\right]_{\mathrm{ads}}}{2 k_{8} k_{6}[\mathrm{SC}]}$

$K_{2}^{\prime}=\frac{4 k_{8} \Phi}{k_{3}\left[\mathrm{O}_{2}\right]_{\mathrm{ads}}\left(k_{2}\left[\mathrm{H}_{2} \mathrm{O}\right]_{\mathrm{ads}}+k_{5}[\mathrm{SC}]\right)}$

$K_{3}=\frac{k_{7}}{k_{6}[\mathrm{SC}]}$

The rate of degradation of the spores is assumed proportional to the spore concentration and to the $[\bullet \mathrm{OH}]$ radical species concentration (reaction step (7)):

$\frac{d[\mathrm{~N}]}{d t}=-k_{7}[\bullet \mathrm{OH}][\mathrm{N}]$

Substitution of Eq. (8) in Eq. (9), after a slight rearrangement gives:

$\frac{d[\mathrm{~N}]}{d t}=-K_{1}^{\prime} \frac{[\mathrm{N}]}{\left(1+K_{3}[\mathrm{~N}]\right)}\left(\sqrt{1+K_{2}^{\prime} e^{a, s}}-1\right)$

where

$K_{1}^{\prime}=k_{7} K_{1}^{\prime \prime}$

Eq. (10) can be easily integrated, and after a slight rearrangement gives:

$[\mathrm{N}]=\left[\mathrm{N}_{0}\right] \exp \left\{K_{3}\left(\left[\mathrm{~N}_{0}\right]-[\mathrm{N}]\right)-K_{1}\left(\sqrt{K_{2}+e^{a, s}}-\sqrt{K_{2}}\right) t\right\}$

where

$K_{1}=K_{1}^{\prime} \sqrt{K_{2}^{\prime}}$
$K_{2}=\frac{1}{K_{2}^{\prime}}$

The final set of adjustable kinetic parameters is $\left\{K_{1}, K_{2}, K_{3}\right\}$.

\subsection{Radiation field model}

Photon absorption in the $\mathrm{TiO}_{2}$ films is essential to the initial step of photocatalytic reaction sequences, and the kinetics of these processes depends on the local superficial rate of photon absorption (LSRPA or $e^{a, s}$ ) [47]. Since the $e^{a, s}$ values cannot be experimentally measured, a radiation field model was devised, which takes into account the radiation emission from the lamps, its propagation in the irradiation compartment, its attenuation in the borosilicate glass at the top of this compartment, and finally the absorption of photons in the $\mathrm{TiO}_{2}$ films. The effects that were considered in the radiation model are schematically represented in Fig. 5.

For the mesh generation, the irradiation compartment volume was defined as a parallelepiped, from which the lamp volumes, defined as cylinders, were subtracted (Fig. 6). In order to simplify the calculations, the borosilicate glass that separates the interior of the irradiation compartment from the lamps was omitted, but the attenuation effect that it produces on radiation flux was incorporated in a subsequent step. The dimensions and configuration were defined to reproduce those of the experimental setup. Afterwards, the irradiation compartment was divided into about $1.5 \times 10^{5}$ tetrahedral cells using the Gambit mesh generator.

The radiative transfer equation (RTE) was solved by means of the discrete ordinate method (DOM) using the Fluent Software (Fluent 6.3). The boundary conditions were considered as follows: 


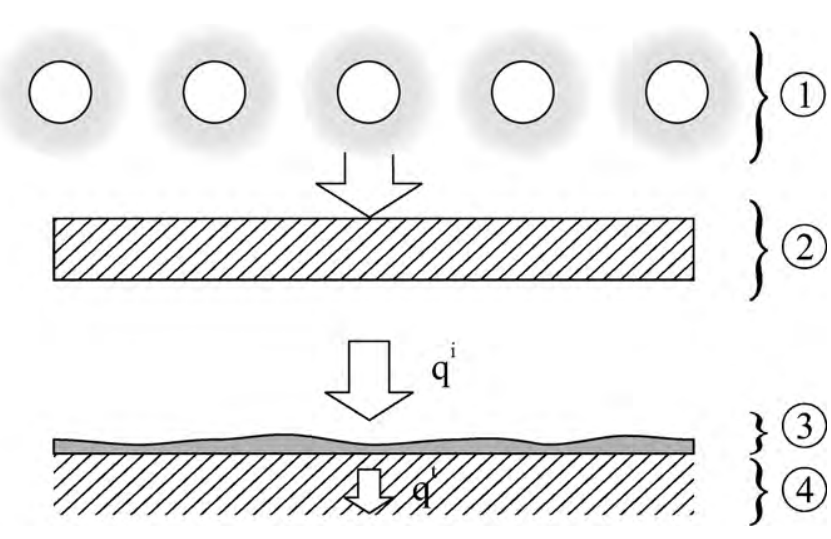

Fig. 5. Physical effects taken into account in the radiation model: (1) emission of UV radiation by the lamps, (2) partial attenuation of radiation in the borosilicate glass window, (3) radiation absorption in the $\mathrm{TiO}_{2}$ films, (4) radiation transmitted through the $\mathrm{TiO}_{2}$ films.

(i) To describe the lamps, a net entrance of isotropic radiative energy flux was defined on the cylindrical surfaces. The radiation flux at the lamp surface was evaluated as:

$q_{\text {lamp }}=\frac{P_{\text {eff,lamp }}}{2 \pi R_{\text {lamp }} L_{\text {lamp }}}$

where $q_{\text {lamp }}$ is the radiation flux at the lamp's surface, $P_{\text {eff,lamp }}$ is the effective emission power of the lamps, $R_{\text {lamp }}$ is the lamp radius, and $L_{\text {lamp }}$ is the lamp length.

(ii) To describe the black walls of the irradiation compartment (described in Section 2), the opaque property was selected for the external walls.

The propagation directions of the radiation were discretized into 10 divisions for both the azimuthal and polar angles. The RTE was uncoupled from the energy transfer equation by considering the system as isothermal. To guarantee the convergence of the numerical solution, a number of iterations equal to $1.0 \times 10^{3}$ was used. The values of the computed radiation flux incident at the different nodes of the plane where the spore samples were located, covering the entire irradiation compartment $(21 \mathrm{~cm} \times 24 \mathrm{~cm})$, are represented in Fig. 7 as a gradation of grays, where the darker zones correspond to

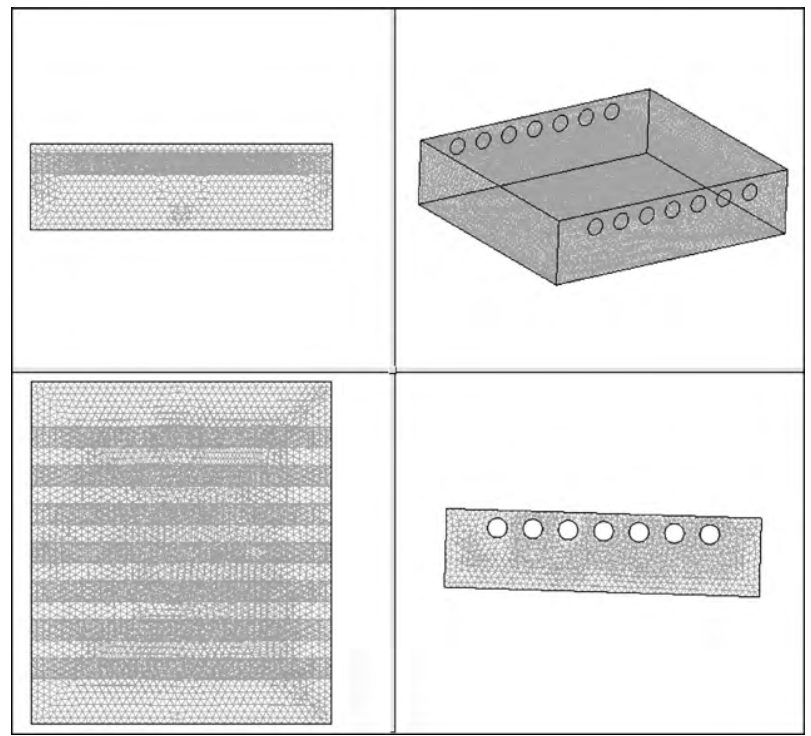

Fig. 6. Mesh used to describe the irradiation compartment and the UV-radiation emitting system.

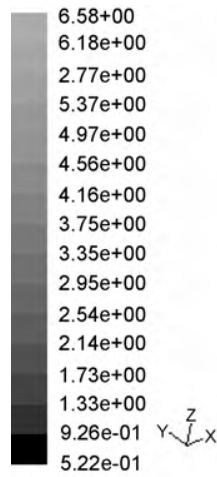

(a)
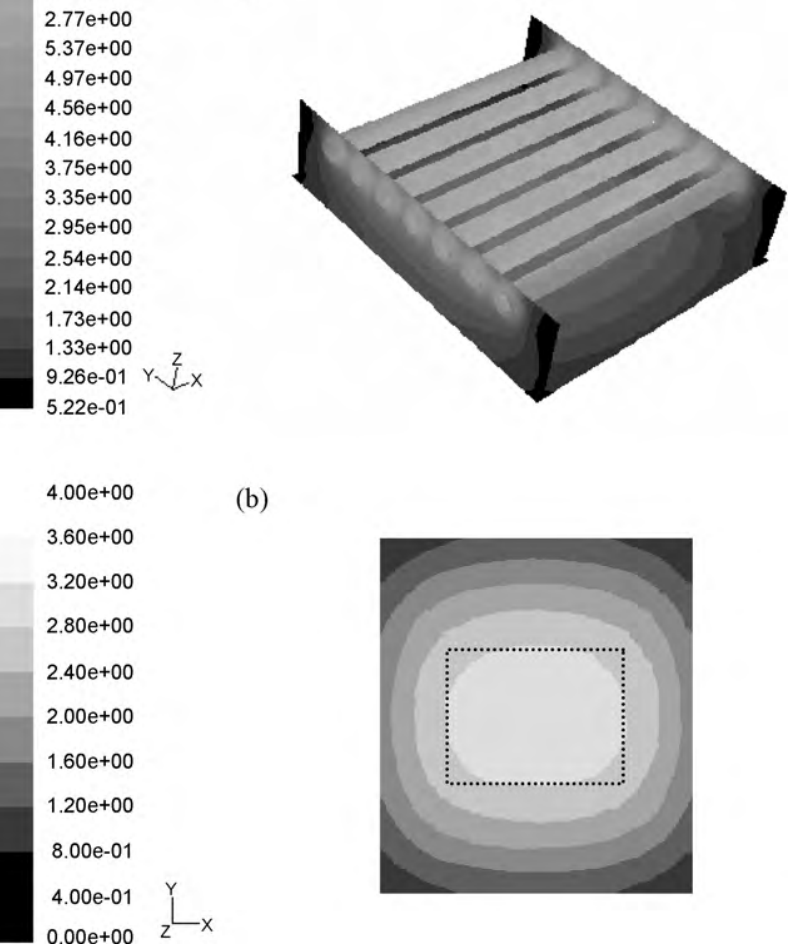

(b)

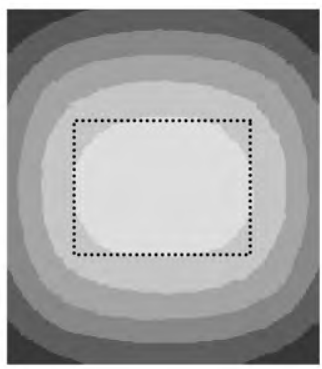

Fig. 7. Radiative energy flux on the irradiation compartment cross section represented by a gradation of grays. The heavy-bordered rectangle at the center represents the size and shape of the sample plates.

the less-illuminated regions. For validation purposes, the predicted values of the local radiation flux obtained with CFD simulations were compared with experimental results. For this, local measurements of the radiation flux incident at different positions on a plane were made using a radiometer (IL 1700 - SED005 - WBS 320). These measurements were carried out placing the radiometer sensor facing the energy emitting system, at different nodes of a plane virtual mesh located at a $4.5 \mathrm{~cm}$ distance from the plane containing the axis of the lamps. The agreement between simulated and experimental results was satisfactory, with an average relative error of $11 \%$.

When comparing the local radiative flux at different locations of the irradiation compartment, significant variations can be observed. Considering the entire irradiation compartment area, the predicted maximum flux of radiative energy at its center is $62 \%$ larger than the minimum flux, at the corners. The lack of uniformity of the irradiation level of spore samples is undesirable because those samples located in the less-illuminated regions will not exhibit the same photocatalytic activity as samples located in the more-illuminated regions; this may leads to erroneous conclusions if the potential of the UV irradiated $\mathrm{TiO}_{2}$ for the spore's inactivation is underestimated. To avoid these difficulties, an irradiation surface of smaller size than that of the complete cross section of the irradiation compartment was used. To ensure that the entire photocatalytic layer will be active in each experimental run, only the most illuminated surface $(9 \mathrm{~cm} \times 12 \mathrm{~cm})$ was used, placed at central zone of the irradiation compartment (Fig. 7). The criterion for this decision was that in order to ensure a reasonably uniform LSRPA over the active film, a tolerable difference between the most illuminated site on the sample plate and the less-illuminated one should be less than $17 \%$.

To consider the attenuation of the radiation that takes place in the borosilicate glass, the absorption of radiation was discounted from the obtained radiation flux because, as mentioned, this effect was not considered in the CFD model. The attenuated radiation that 


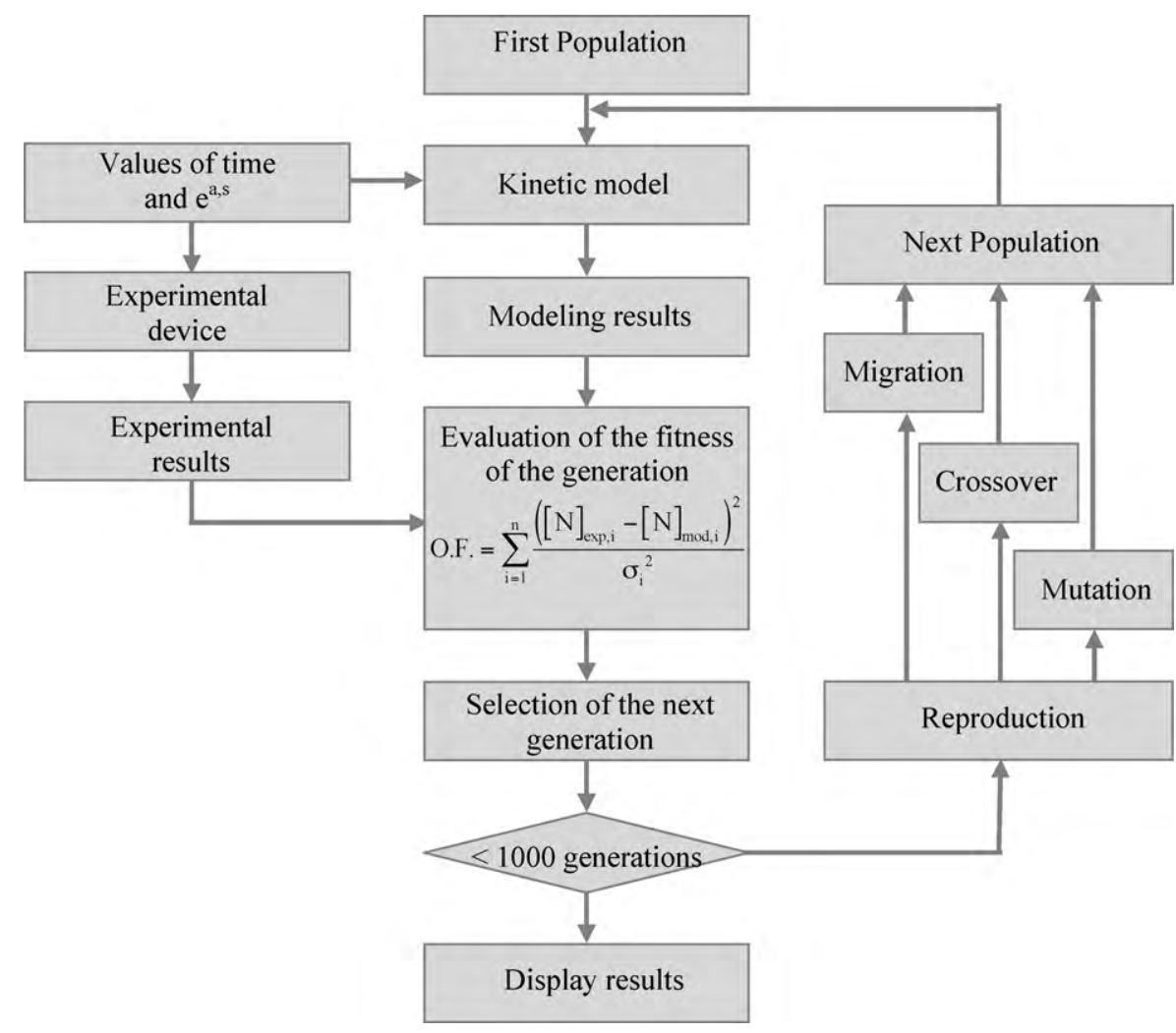

Fig. 8. Schematic diagram of the genetic algorithm employed to obtain the parameters of the kinetic models.

actually reaches the $\mathrm{TiO}_{2}$ films can be calculated from:

$q^{i}(\underline{x})=q^{0}(\underline{x}) \exp \left(-\left\langle\kappa_{\lambda, g}\right\rangle_{\lambda_{\text {lamp }}} e_{g}\right)$

where $q^{i}(\underline{x})$ is the effective radiation that reaches the $\mathrm{TiO}_{2}$ films, $q^{0}(\underline{x})$ represents the radiation flux obtained from the CFD simulations, $\left\langle\kappa_{\lambda, g}\right\rangle_{\lambda_{\text {lamp }}}$ is the absorption coefficient of the borosilicate glass, and $e_{g}$ is the thickness of the glass plate. The product of $\left\langle\kappa_{\lambda, g}\right\rangle_{\lambda_{\text {lamp }}} e_{g}$ was obtained from spectrophotometric measurements of the transmittance of the bare borosilicate glass plates (Fig. 2).

By setting up local radiative energy balances in terms of local energy fluxes (Fig. 5), the LSRPA was computed at each point of the catalytic film supported on the glass plate [47]:

$e^{a, s}(\underline{x})=q^{i}(\underline{x})-q^{t}(\underline{x})$

In Eq. (14), $q^{i}(\underline{x})$ stands for the local radiative flux that reaches the catalytic surface and $q^{t}(\underline{x})$ is the local radiative energy flux that is transmitted through the $\mathrm{TiO}_{2}$ films. By subtracting the radiation attenuation in the $\mathrm{TiO}_{2}$ films from the radiation flux reaching those films, the rate of photon absorption can be calculated as follows:

$e^{a, s}(\underline{x})=q^{i}(\underline{x})\left[1-\exp \left(-\left\langle\kappa_{\lambda, f}\right\rangle_{\lambda_{\text {lamp }}} e_{f}\right)\right]$

\subsection{Regression of kinetic parameters}

In the section where the kinetic model was analyzed, a kinetic expression was obtained (Eq. (11)). The kinetic parameters of that expression were fitted by employing the complete set of experimental results. The objective function (OF) to be minimized was defined as the summation over all experimental points of the squared differences between each experimental value of the concentration of viable spores and the corresponding value calculated with the kinetic expressions divided by the standard deviation of the experimental value:

$\mathrm{OF}\left(K_{1}, K_{2}, K_{3}\right)=\sum_{i=1}^{n} \frac{\left([\mathrm{N}]_{\mathrm{exp}, i}-[\mathrm{N}]_{\mathrm{mod}, i}\right)^{2}}{\sigma_{i}^{2}}$

The set $\left(K_{1}, K_{2}, K_{3}\right)$ of kinetic parameters values that minimizes the OF was considered the best-fit. In order to find this value, the genetic algorithm (GA) was used. In general terms, the GA is an adaptive heuristic search algorithm inspired on evolution, natural selection, and genetics. This minimization method was selected because it is capable of finding the absolute minimum of a given OF rather than its local minima, as most of the alternative methods do. A simplified scheme of the employed algorithm is shown in Fig. 8. The initial step consisted of the generation of the first population of 100 individuals (i.e., a group of values of the kinetic parameters $K_{1}$, $K_{2}$, and $K_{3}$ ) by random. By using the experimental results and the predicted values of the complete set of examined operating conditions, the fitness (i.e., the objective function) of each individual (i.e., each kinetic parameter value) was computed. The fittest individuals, those that have the smaller OF values, were selected to survive and were used to calculate the next generation. The next generation was computed by changing the selected group of parameter by migration, crossover, and mutation at random. Then, the OF was evaluated for the complete population of groups of parameters. This iterative process was repeated until the convergence of the parameters to those that minimize the OF. The parameter values obtained with the GA for Eq. (11) are shown in Table 4.

Table 4

Kinetic parameters.

\begin{tabular}{lll}
\hline Parameter & Value & Units \\
\hline$K_{1}$ & 123.76 & $\mathrm{~cm} \mathrm{Einstein}^{-1 / 2} \mathrm{~h}^{-1 / 2}$ \\
$K_{2}$ & $2.53 \times 10^{-9}$ & Einstein h$^{-1} \mathrm{~cm}^{-2}$ \\
$K_{3}$ & $1.95 \times 10^{-27}$ & $\mathrm{~cm}^{2} \mathrm{CFU}^{-1}$ \\
\hline
\end{tabular}



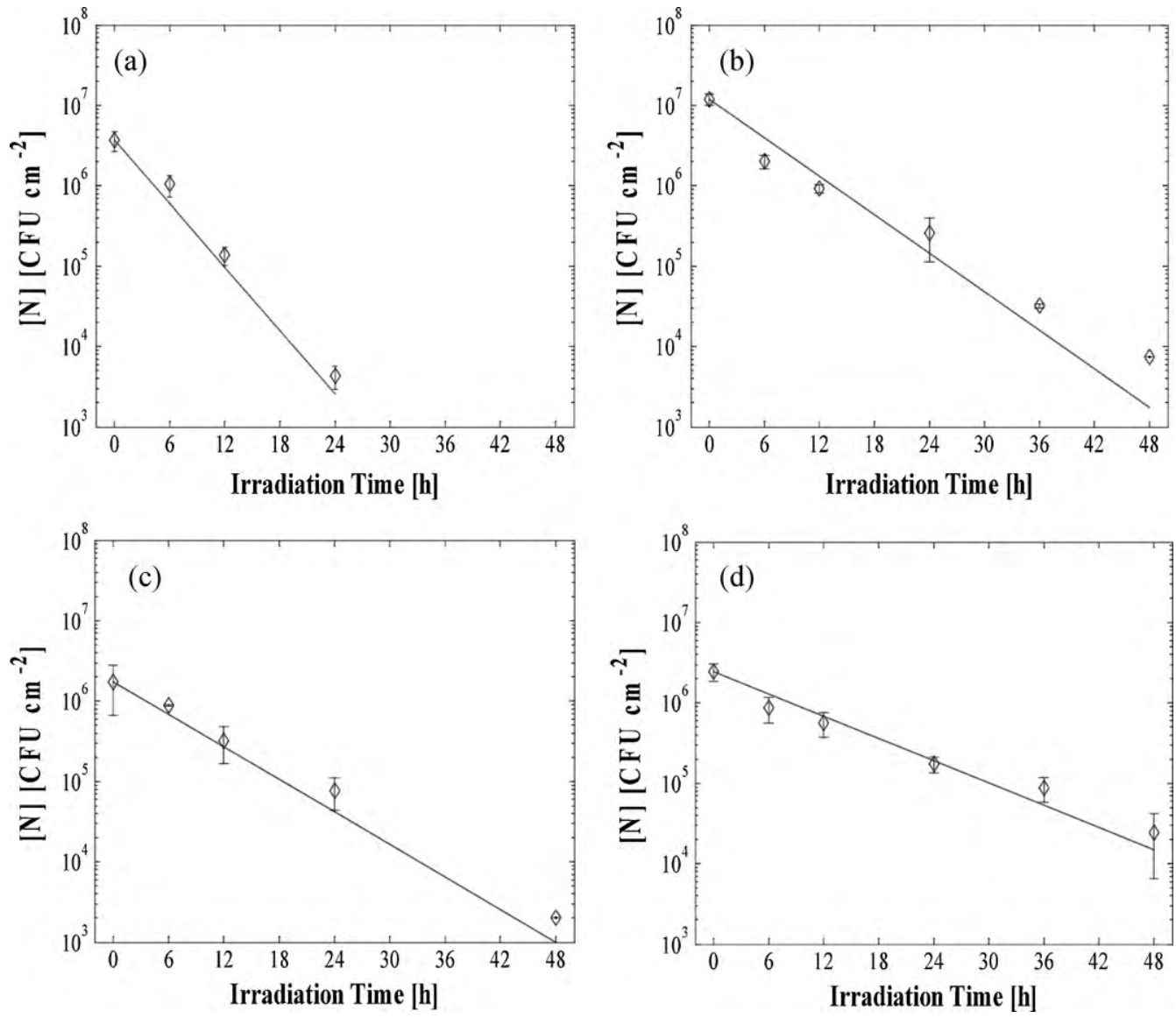

Fig. 9. Spore inactivation curves for different values of the incident radiation flux: (a) 2.44 , (b) $0.90,(c) 0.63$ and (d) 0.29 mW $\mathrm{cm}^{-2}$, ( $\left.\diamond\right)$ experimental values, $(-)$ model predicted values.

From Table 4, it is possible to conclude that the terms affected by $K_{2}$ and $K_{3}$ can be neglected in Eq. (11). Then, the final kinetic equation is

$$
[\mathrm{N}]=\left[\mathrm{N}_{0}\right] \exp \left(-K_{1} \sqrt{e^{a, s}} t\right)
$$

After analyzing the resulting equation obtained, it can be seen that the inactivation rate has a square root dependence on the absorbed radiation by the photocatalyst film $\left(e^{a, s}\right)$.

The inactivation curves of spores of $B$. subtilis for different values of incident radiation flux used in this work and the values obtained by the developed model (Eq. (17)) are shown in Fig. 9. There is a

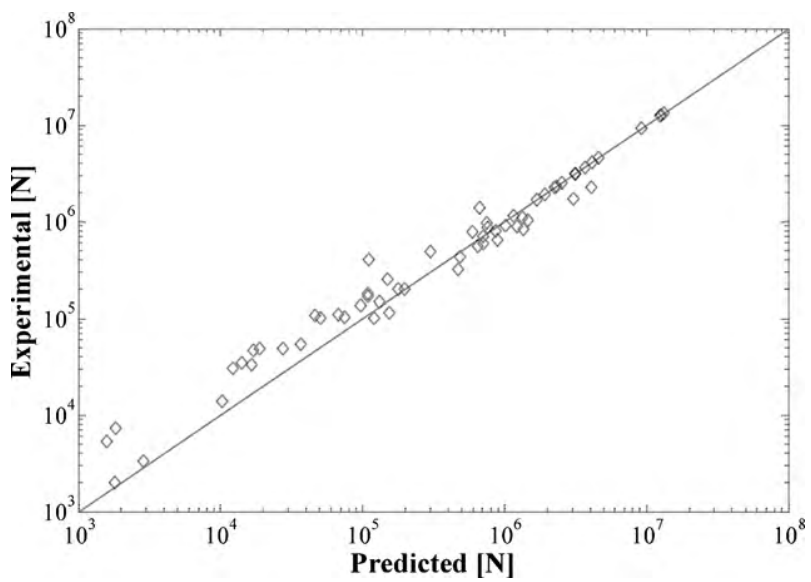

Fig. 10. Comparison between model prediction and experimental values of viable spores obtained before and after the irradiation process. good agreement between the experimental data and model predictions. Similarly, Fig. 10 compares the experimental results with those predicted by the kinetic model, for all the experimental data obtained in this work.

\section{Conclusions}

In this work, the photocatalytic and the photochemical inactivation of spores of $B$. subtilis were measured. The spores were spread on bare borosilicate glass plates and on plates covered with thin $\mathrm{TiO}_{2}$ films, and then were subjected to UV-A irradiation with different levels $\left(2.44-0.29 \mathrm{~mW} \mathrm{~cm}^{-2}\right)$ during different times $(0,6,12$, $24,36,48 \mathrm{~h})$.

The experimental results showed a meaningful reduction of the viability of the spores immobilized on the $\mathrm{TiO}_{2}$-covered plates after the irradiation period ( 3 orders of magnitude after $24 \mathrm{~h}$ under $2.44 \mathrm{~mW} \mathrm{~cm}^{-2}$ of continuous irradiation), confirming the viability of spore photocatalytic inactivation as a disinfection technology. On the contrary, the viability of the spores that were spread on bare borosilicate glass plates had no significant changes after being subjected to UV-A irradiation ( 0.47 orders of magnitude after $48 \mathrm{~h}$ under $2.44 \mathrm{~mW} \mathrm{~cm}^{-2}$ of continuous irradiation), ruling out the possibility of purely photochemical spore inactivation resulting from this type of radiation.

A detailed radiation field model was developed, that allowed the calculation of the local superficial rate of photon absorption (LSRPA) at any point on the $\mathrm{TiO}_{2}$ film, and a kinetic model for the spore inactivation process was derived from a simplified pathway that allows the calculation of the local rate of spore inactivation. The results predicted with the kinetic model agreed quite satisfactorily 
with the experimental results, for different exposition times and irradiation fluxes.

\section{Acknowledgments}

The authors would like to thank Universidad Nacional del Litoral, Consejo Nacional de Investigaciones Científicas y Técnicas and Agencia Nacional de Promoción Científica y Tecnológica for their financial support. Thanks are also given to Eng. Gerardo Rintoul, for his participation in some parts of the experimental work, and to the Professors Maria C. Lurá and Juan C. Claus for their valuable support.

\section{References}

[1] American Thoracic Society, Environmental controls and lung disease, American Review of Respiratory Disease 142 (1990) 915.

[2] P.R. Morey, J.C. Feeley, J.A. Otten, Biological contaminants in indoor environments, ASTM (1990).

[3] J. Peral, D.F. Ollis, Heterogeneous photocatalytic oxidation of gas-phase organics for air purification: acetone, 1-butanol, butyraldehyde, formaldehyde, and $\mathrm{m}$-xylene oxidation, Journal of Catalysis 136 (1992) 554-565.

[4] M.R. Hoffmann, S.T. Martin, W. Choi, D.W. Bahnemann, Environmental applications of semiconductor photocatalysis, Chemical Reviews 95 (1995) 69-96.

[5] A. Mills, S. Le Hunte, An overview of semiconductor photocatalysis, Journal of Photochemistry and Photobiology A: Chemistry 108 (1997) 1-35.

[6] D.M. Blake, Bibliography of Work on the Heterogeneous Photocatalytic Removal of Hazardous Compounds from Water and Air 2001, National Renewable Energy Laboratory, Golden, Colorado, 1999.

[7] A. Fujishima, T.N. Rao, D.A. Tryk, Titanium dioxide photocatalysis, Journal of Photochemistry and Photobiology C: Photochemistry Reviews 1 (2000) 1-21.

[8] H. de Lasa, B. Serrano, M. Salaices, Photocatalytic Reaction Engineering, Springer, New York, 2005

[9] M.S. Vohra, A.A. Malik, M.S. Al-suwaiyan, A.A. Bukhari, $\mathrm{TiO}_{2}$-assisted photocatalytic removal of phenol: effect of co-pollutants, International Journal of Applied Environmental Sciences 4 (2009) 33-45.

[10] T.Matsunaga, R. Tomoda, T. Nakajima, H. Wake, Photoelectrochemical sterilization of microbial cells by semiconductor powders, FEMS Microbiology Letters 29 (1985) 211-214.

[11] Y. Horie, D.A. David, M. Taya, S. Tone, Effects of light intensity and titanium dioxide concentration on photocatalytic sterilization rates of microbial cells, Industrial \& Engineering Chemistry Research 35 (1996) 3920-3926.

[12] Y. Horie, M. Taya, S. Tone, Effect of cell adsorption on photosterilization of Escherichia coli over titanium dioxide-activated charcoal granules, Journal of Chemical Engineering of Japan 31 (1998) 922-929.

[13] Y. Horie, M. Taya, S. Tone, Evaluation of photocatalytic sterilization rates of Escherichia coli cells in titanium dioxide slurry irradiated with various light sources, Journal of Chemical Engineering of Japan 31 (1998) 577-584.

[14] D.M. Blake, P.-C. Maness, Z. Huang, E.J. Wolfrum, J. Huang, Application of the photocatalytic chemistry of titanium dioxide to disinfection and the killing of cancer cells, Separation and Purification Methods 28 (1999) 1-50.

[15] P.-C. Maness, S. Smolinski, D.M. Blake, Z. Huang, E.J. Wolfrum, W.A. Jacoby, Bactericidal activity of photocatalytic $\mathrm{TiO}_{2}$ reaction: toward an understanding of its killing mechanism, Applied and Environmental Microbiology 65 (1999) 4094-4098.

[16] Y. Koizumi, J. Nishi, M. Taya, Kinetic analysis of photosterilization rate of Escherichia coli cells in titanium dioxide suspensions associated with redox reactions of iron ions, Journal of Chemical Engineering of Japan 34 (2001) 1381-1386.

[17] Y. Koizumi, J. Nishi, M. Taya, Photosterilization of Escherichia coli cells using iron-doped titanium dioxide particles, Journal of Chemical Engineering of Japan 35 (2002) 299-303.

[18] K. Sunada, T. Watanabe, K. Hashimoto, Studies on photokilling of bacteria on $\mathrm{TiO}_{2}$ film, Journal of Photochemistry and Photobiology A: Chemistry 156 (2003) 227-233.

[19] A.G. Rincoinn, C. Pulgarin, Effect of pH, inorganic ions, organic matter and $\mathrm{H}_{2} \mathrm{O}_{2}$ on $E$. coli $\mathrm{K} 12$ photocatalytic inactivation by $\mathrm{TiO}_{2}$ : implications in solar water disinfection, Applied Catalysis B: Environmental 51 (2003) 283-302.

[20] A.G. Rincoin, C. Pulgarin, Use of coaxial photocatalytic reactor (CAPHORE) in the $\mathrm{TiO}_{2}$ photo-assisted treatment of mixed E. coli and Bacillus sp. and bacterial community present in wastewater, Catalysis Today 101 (2005) $331-344$.
[21] J. Marugán, R. van Grieken, C. Sordo, C. Cruz, Kinetics of the photocatalytic disinfection of Escherichia coli suspensions, Applied Catalysis B: Environmental 82 (2008) 27-36.

[22] R. van Grieken, J. Marugán, C. Sordo, C. Pablos, Comparison of the photocatalytic disinfection of $E$. coli suspensions in slurry, wall and fixed-bed reactors, Catalysis Today 144 (2009) 48-54.

[23] E.R. Bandala, B. Corona-Vasquez, R. Guisar, M. Uscanga, Deactivation of highly resistant microorganisms in water using solar driven photocatalytic processes, International Journal of Chemical Reactor Engineering 7 (2009) A7.

[24] D.Y. Goswami, D.M. Trivedi, S.S. Block, Photocatalytic disinfection of indoor air Solar Engineering-ASME 1 (1997) 421-427.

[25] W.A. Jacoby, P.C. Maness, E.J. Wolfrum, D.M. Blake, J.A. Fennell, Mineralization of bacteria cell mass on a photocatalytic surface in air, Environmental Science \& Technology 32 (1998) 2650-2653.

[26] T.K. Goswami, S.K. Hingorani, H. Greist, Photocatalytic system to destroy bioaerosols in air, Journal of Advanced Oxidation Technologies 4 (1999) $185-188$.

[27] E.J. Wolfrum, J. Huang, D.M. Blake, P. Maness, Z. Huang, J. Fiest, Photocatalytic oxidation of bacteria, bacterial and fungal spores, and model biofilm components to carbon dioxide on titanium dioxide coated surfaces, Environmental Science and Technology 36 (2002) 3412-3419.

[28] H.T Greist, S.K. Hingorani, K. Kelley, D.Y. Goswami, Using scanning electron microscopy to visualize photocatalytic mineralization of airborne microorganisms, Indoor Air (2002).

[29] T. Sato, Y. Koizumi, M. Taya, Photocatalytic deactivation of airborne microbial cells on $\mathrm{TiO}_{2}$-loaded plate, Biochemical Engineering Journal 14 (2003) 149-152.

[30] C.Y. Lin, C.S. Li, Inactivation of microorganisms on the photocatalytic surfaces in air, Aerosol Science and Technology 37 (2003) 939-946.

[31] A. Pal, X. Min, L.E. Yu, S.O. Pehkonen, M. Ray, Photocatalytic inactivation of bioaerosols by $\mathrm{TiO}_{2}$ coated membrane, International Journal of Chemical Reactor Engineering 3 (2005) A45.

[32] A. Vohra, D.Y. Goswami, D.A. Deshpande, S.S. Block, Enhanced photocatalytic inactivation of bacterial spores on surfaces in air, Journal of Industrial Microbiology Biotechnology 32 (2005) 364-370.

[33] A. Vohra, D.Y. Goswami, D.A. Deshpande, S.S. Block, Enhanced photocatalytic disinfection of indoor air, Applied Catalysis B: Environmental 64 (2006) 57-65.

[34] A. Erkan, U. Bakir, G. Karakas, Photocatalytic microbial inactivation over Pd doped $\mathrm{SnO}_{2}$ and $\mathrm{TiO}_{2}$ thin films, Journal of Photochemistry and Photobiology A: Chemistry 184 (2006) 313-321.

[35] S.A. Grinshpun, A. Adhikari, T. Honda, K.Y. Kim, M. Toivola, K.S. Ramchander Rao, T. Reponen, Control of aerosol contaminants in indoor air: combining the particle concentration reduction with microbial inactivation, Environmental Science \& Technology 41 (2007) 606-612.

[36] A. Pal, S.O. Pehkonen, L.E. Yu, M.B. Ray, Photocatalytic inactivation of airborne bacteria in a continuous-flow reactor, Industrial \& Engineering Chemistry Research 47 (2008) 7580-7585.

[37] M.P. Paschoalino, W.F. Jardim, Indoor air disinfection using a polyester supported $\mathrm{TiO}_{2}$ photo-reactor, Indoor Air 18 (2008) 473-479.

[38] J. Zhao, V. Krishna, B. Hua, B. Moudgil, B. Koopman, Effect of UV-A irradiance on photocatalytic and UV-A inactivation of Bacillus cereus spores, Journal of Photochemistry and Photobiology B: Biology 94 (2009) 96-100.

[39] S. Yamazaki-Nishida, K.J. Nagano, L.A. Phillips, S. Cervera-March, M.A. Anderson, Photocatalytic degradation of trichloroethylene in the gas phase using $\mathrm{TiO}_{2}$ pellets, Journal of Photochemical and Photobiology A: Chemical 70 (1993) 95-99.

[40] T.E. Shehata, E.B. Collins, Sporulation and heat resistance of psychrophilic strains of Bacillus, Journal of Dairy Science 55 (1972) 1405-1409.

[41] R. Moeller, G. Horneck, R. Facius, E. Stackebrandt, Role of pigmentation in protecting Bacillus sp. endospores against environmental UV radiation, FEMS Microbiology Ecology 51 (2005) 231-236.

[42] A. Atrih, S.J. Foster, Bacterial endospores the ultimate survivors, International Dairy Journal 12 (2002) 217-223.

[43] D.D. Sun, J.H. Tay, K.M. Tan, Photocatalytic degradation of E. coliform in water, Water Research 37 (2003) 3452-3462.

[44] M. Cho, H. Chung, W. Choi, J. Yoon, Different inactivation behaviors of MS2 phage and Escherichia coli in $\mathrm{TiO}_{2}$ photocatalytic disinfection, Applied and Environmental Microbiology 71 (2005) 270-275.

[45] K.-P.Yu, G.W.-M. Lee, S.-Y. Lin, C.P. Huang, Removal of bioaerosols by the combination of a photocatalytic filter and negative air ions, Journal of Aerosol Science 39 (2008) 377-392.

[46] M. Cho, H. Chung, W. Choi, J. Yoon, Linear correlation between inactivation of E. coli and $\mathrm{OH}$ radical concentration in $\mathrm{TiO}_{2}$ photocatalytic disinfection, Water Research 38 (2004) 1069-1077.

[47] G. Imoberdorf, H.A. Irazoqui, A.E. Cassano, O.M. Alfano, Photocatalytic degradation of tetrachloroethylene in gas phase on $\mathrm{TiO}_{2}$ films: a kinetic study, Industrial \& Engineering Chemistry Research 44 (2005) 6075-6085. 